\title{
Expression of the immediate-early gene-encoded protein Egr-1 (zif268) during in vitro classical conditioning
}

\author{
Maxim Mokin and Joyce Keifer ${ }^{1}$ \\ Neuroscience Group, Division of Basic Biomedical Sciences, University of South Dakota School of Medicine, \\ Vermillion, South Dakota 57069, USA
}

\begin{abstract}
Expression of the immediate-early genes (IEGs) has been shown to be induced by activity-dependent synaptic plasticity or behavioral training and is thought to play an important role in long-term memory. In the present study, we examined the induction and expression of the IEG-encoded protein Egr-1 during an in vitro neural correlate of eyeblink classical conditioning. The results showed that Egr-1 protein expression as determined by immunocytochemistry and Western blot analysis rapidly increased during the early stages of conditioning and remained elevated during the later stages. Further, expression of Egr-1 protein required NMDA receptor activation as it was blocked by bath application of AP-5. These findings suggest that the IEG-encoded proteins such as Egr-1 are activated during relatively simple forms of learning in vertebrates. In this case, Egr-1 may have a functional role in the acquisition phase of conditioning as well as in maintaining expression of conditioned responses.
\end{abstract}

Expression of the immediate-early genes (IEGs) has been shown to be induced by activity-dependent synaptic plasticity or behavioral training and is thought to play an important role in longterm memory (Steward et al. 1998; Guzowski et al. 2001; O'Brien et al. 2002). The IEGs encode two classes of effectors, regulatory transcription factors and a variety of proteins that act on diverse cellular processes. The IEGs that have been of particular interest due to their close association with synaptic plasticity and learning include Arc (activity-regulated cytoskeletal-associated gene; aka $\operatorname{Arg} 3.1), E g r-\overline{1}$ (early growth response gene; aka zif268), and Narp (neuronal activity regulated pentraxin). For example, Arc protein expression has been associated with spatial learning tasks and maintenance of long-term potentiation (LTP) (Guzowski et al. 2000). Arc mRNA expression is also rapidly induced by high-frequency stimulation in hippocampal slices where it becomes targeted to dendritic segments receiving the stimulation (Steward et al. 1998; Steward and Worley 2001). The selective positioning of $\operatorname{Arc}$ mRNA to active synapses is an NMDA receptor-mediated process; local application of NMDA receptor antagonists blocks mRNA induction at dendritic sites of drug application. The functional significance of Arc mRNA targeting to active synapses is unknown, but it is likely to serve in protein synthesis-dependent modification of synapses. Other studies have suggested that IEGs regulate AMPA receptor trafficking. Evidence in favor of this hypothesis comes from studies of another IEG, Narp, which is an essential factor in AMPA receptor clustering at excitatory synapses in culture ( $\mathrm{O}^{\prime}$ Brien et al. 2002).

Egr-1 was initially identified as having a link with cellular growth and differentiation processes by studies aimed at examining nerve growth factor (NGF)-induced gene expression (for a review, see O'Donovan et al. 1999). Later studies showed that Egr-1 was also induced by synaptic activity. LTP in the hippocampus resulted in significantly increased mRNA expression for $E g r-1$ but not for $c$-fos, $c$-jun, or jun-B, and this response was NMDA receptor dependent (Cole et al. 1989; Wisden et al. 1990).

'Corresponding author.

E-mail jkeifer@usd.edu; fax (605) 677-6381.

Article and publication are at http://www.learnmem.org/cgi/doi/10.1101/ Im.87305.
Behavioral training studies have demonstrated a rapid and transient increase in hippocampal Egr-1 mRNA after spatial learning tasks in rats (Guzowski et al. 2001), and in songbirds, expression of the homologous gene zenk increased sharply in the auditory nuclei of birds that listened to unfamiliar calls and declined when calls became familiar (Mello et al. 1995; Brauth et al. 2002). Egr-1 expression has also been implicated in having a key role in memory consolidation and/or reconsolidation processes. A targeted mutation producing a zif $268^{-/-}$mutant mouse model resulted in impaired long-term memory in both spatial and nonspatial learning tasks in animals tested $24-48 \mathrm{~h}$ after training compared with heterozygous and wild-type littermates (Jones et al. 2001). Correspondingly, late LTP, when tested after the same time period in that study, was absent. A more detailed analysis of the behavioral results suggests that Egr-1 may be required not for consolidation of learned information into long-term memory but for reconsolidation of memories once retrieved (Bozon et al. 2003). These findings agree well with those from a recent study showing impaired reconsolidation, but not consolidation, of contextual fear conditioning in rats treated with Egr-1 antisense oligodeoxynucleotides injected into the hippocampus (Lee et al. 2004).

The above studies indicate a role for Egr-1 in complex aspects of learning and memory. Delay classical conditioning is a relatively simple form of associative learning that is not hippocampus or forebrain dependent, can be generated independently of context, and relies on relatively simpler and well-defined neural machinery involving cerebellar and brain stem circuitry compared with other more complex forms of learning (Clark et al. 2002; Christian and Thompson 2003). Acquisition of mammalian eyeblink conditioning requires protein synthesis (Bracha et al. 1998), and retention is associated with synapse formation (Kleim et al. 2002). Recent studies using an in vitro neural correlate of eyeblink classical conditioning have further shown that AMPA receptor trafficking and enhanced synthesis of specific receptor subunits may underlie acquisition of conditioned responses (CRs) in that preparation (Mokin and Keifer 2004a). Therefore, activation of gene expression is generally considered to underlie mechanisms of conditioning. Little is known about 
the expression of the IEG-encoded proteins during eyeblink classical conditioning, although the distribution of c-fos expression following conditioning of the rabbit nictitating membrane response has been mapped (Irwin et al. 1992; Carrive et al. 1997). Because Egr-1 expression is implicated in complex forms of learning and because the IEGs may have a role in receptor trafficking at synapses, we were interested in determining whether $E g r-1$ was also expressed during a simpler type of learning in a reduced preparation. Therefore, the present study investigated the properties of Egr-1 protein expression during in vitro abducens classical conditioning by using a delay-like, short trace, paradigm that does not require the hippocampus or cerebellum for acquisition of CRs. This model utilizes an isolated brain stem preparation that consists of the pontine blink circuitry (Zhu and Keifer 2004), in which auditory nerve stimulation (the tone) is paired with trigeminal nerve stimulation (the airpuff). Paired stimuli of these cranial nerves produces an in vitro neural correlate of a conditioned eyeblink response recorded from the abducens nerve in which CR acquisition is rapid and NMDA receptor dependent (Anderson and Keifer 1999; Keifer 2001; Keifer and Clark 2003; for a review, see Keifer 2003). The results reported here show that Egr-1 protein expression, as determined by immunocytochemistry and Western blot analysis, rapidly increases during the early stages of conditioning and remains elevated during the later stages. Further, expression of Egr-1 protein requires NMDA receptor activation. These findings suggest that the IEGencoded proteins such as Egr-1 are activated during relatively simple as well as complex forms of learning in vertebrates and may have diverse functional roles.

\section{Results}

\section{Antibody specificity}

The specificity of the Egr-1 primary antibody was tested by the procedures shown in Figure 1. Western blotting was performed on turtle and rat brain tissue. In both species the antibody labeled a single band that migrated to $\sim 80 \mathrm{kDa}$, which corresponds to the molecular weight of the Egr-1 protein (Fig. 1, lanes 1,2). In the presence of Egr-1 blocking peptide (1:50, sc-110P; Santa Cruz Biotech), protein staining of turtle brain tissue for Egr-1 was completely blocked and no band was observed (Fig. 1, lane 3), indicating that the antibody raised in mammals maintained its specificity in turtles. Similar findings have been reported for Egr-1 protein in bird brain tissue using the same antibody (Brauth et al. 2002). Furthermore, it was recently shown that Egr-1 from a teleost shares a high sequence homology to other vertebrates (Burmeister and Fernald 2005).

\section{Abducens Egr-1 immunoreactivity increases during conditioning}

Immunoreactivity of the abducens motor nuclei for Egr-1 protein expression in conditioned and pseudoconditioned preparations was examined, and these data are illustrated in Figure 2. Both the conditioned and pseudoconditioned groups were examined at

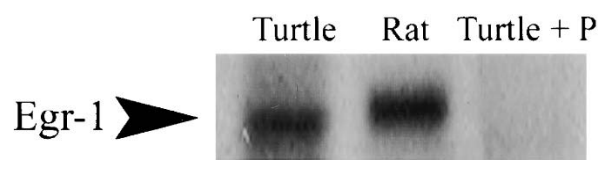

Figure 1. Western blots to test the specificity of the Egr-1 antibody showed a single band that migrated to $\sim 80 \mathrm{kDa}$ for both turtle (lane 1) and rat (lane 2) brain tissue. In the presence of Egr-1 blocking peptide, protein staining of turtle brain tissue was completely blocked and no band was observed (lane 3), indicating that the antibody raised in mammals maintained its specificity in turtles.
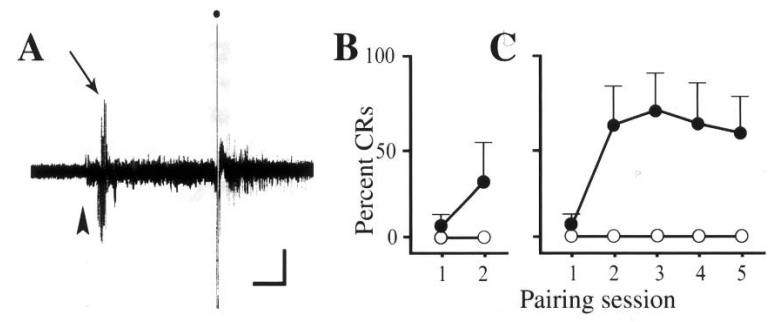

D
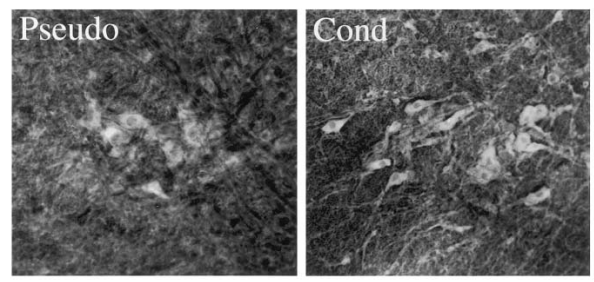

$\mathbf{E}$

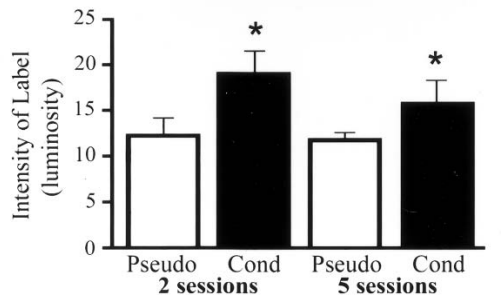

Figure 2. Immunoreactivity of abducens motor neurons to Egr-1 after conditioning or pseudoconditioning. $(A)$ An exemplar abducens nerve recording showing a short latency burst discharge (arrow; the onset of the CS is indicated by the arrowhead) that characterizes CRs of brain stem preparations followed by a UR (the stimulus is indicated by the filled circle). Bar, $50 \mu \mathrm{V}, 0.25 \mathrm{sec}$. ( $B, C$ ) Acquisition curves for preparations that were conditioned (filled circles) or pseudoconditioned (open circles) for two $(B)$ or five $(C)$ pairing sessions. The first session typically shows relatively few CRs, which gradually increase with further conditioning. $(D)$ Photomicrographs of immunolabeled accessory abducens motor neurons from a pseudoconditioned (Pseudo) and conditioned (Cond) preparation. The intensity of immunoreactivity is greater in conditioned preparations, and the labeling of soma and dendritic processes is greatly enhanced. (E) Quantitative data showing significantly increased levels of immunoreactivity of abducens motor neurons for Egr-1 after both two and five sessions of conditioning compared with pseudoconditioned controls (asterisks).

two time points, in the early stages of conditioning after two pairing sessions (or for a total time period of $\sim 1.5 \mathrm{~h}$ after the onset of conditioning) and in the later stages of conditioning after five pairing sessions (for $4.5 \mathrm{~h}$ ). The pseudoconditioned preparations were presented with the same number of stimuli as the conditioned group except that the CS and US were randomly unpaired. A summary of the conditioning data for this series of experiments is shown in Figure 2, A through C. A representative abducens nerve recording from a preparation that exhibited conditioning is shown in Figure 2A. The recording shows an initial short latency burst discharge characteristic of abducens CRs in this in vitro brain stem preparation in response to an auditory nerve CS (Fig. 2A, arrow) followed by the trigeminal nerve evoked unconditioned response (UR) (the US is indicated by the filled circle). Acquisition curves of abducens CRs for preparations that were conditioned or pseudoconditioned for two pairing sessions are summarized in Figure $2 \mathrm{~B}$ and for those conditioned for five sessions in Figure 2C. Preparations conditioned for two pairing sessions demonstrated a mean of $2 \pm 6 \%$ CRs in the first session and $29 \pm 25 \%$ CRs in the second session (Fig. 2B, filled circles). Those conditioned for five sessions showed a mean of $2 \pm 2 \%$ CRs in the first session and an average of $61 \pm 7 \%$ CRs in 
sessions two through five (Fig. 2C). The control preparations that were pseudoconditioned for two and five sessions both demonstrated a mean of $0 \pm 0 \%$ CRs (Fig. 2B,C, open circles). Immunocytochemical localization of Egr-1 protein in the abducens motor nuclei was performed for all of the experimental groups described above. The photomicrographs in Figure 2D show Egr-1 immunopositive neurons in the accessory abducens nucleus from a preparation that was pseudoconditioned for two sessions (Pseudo, Fig. 2D) and a preparation that was conditioned for two sessions (Cond, Fig. 2D). Pseudoconditioned preparations showed light cytoplasmic label and very little labeling of dendrites. Conditioning resulted in increased intensity of label in the cytoplasm of the cell body together with considerably enhanced labeling of the proximal and distal dendrites. Immunoreactivity of abducens motor neurons by using a biotinylated secondary antibody (1:100) also confirmed the localization of Egr-1 staining to the cytoplasm of these neurons (data not shown). Quantitative analysis of the immunoreactivity of abducens motor neurons to Egr-1 protein was performed and these data are summarized in Figure 2E. Findings for the principal and accessory abducens nucleus were not significantly different from one another and therefore these data were combined. The intensity of Egr-1 labeling of the abducens motor nuclei was significantly increased after two pairing sessions in preparations that demonstrated conditioning compared with those that were pseudoconditioned $(P<0.0001)$. Furthermore, Egr-1 immunoreactivity after conditioning was significantly greater than were pseudoconditioned preparations after five sessions $(P<0.03)$. These values were not different from the levels of immunoreactivity after conditioning for two sessions. These data are in contrast to those obtained for Egr-1 immunoreactivity of another nucleus in the abducens eye blink circuit, the principal sensory trigeminal nucleus (Zhu and Keifer 2004). While these neurons were immunopositive for Egr-1, there were no significant changes in the immunoreactivity of this nucleus after conditioning compared with pseudoconditioned preparations ( $P=0.62$; data not shown). Finally, there was a significant positive correlation between the level of Egr-1 immunoreactivity of abducens motor neurons and the level of conditioning after two $\left(R^{2}=0.4, P=0.02\right)$ and five pairing sessions $\left(R^{2}=0.8, P<0.001\right)$. Thus, the immunoreactivity of abducens motor neurons to Egr- 1 protein is significantly increased during the early stages of in vitro conditioning and remains elevated during the later stages.

\section{Conditioning-induced increase in Egr-1 protein expression and NMDA receptor dependency}

Western blot analysis for Egr-1 protein was performed on five groups of brain stem preparations: those that were conditioned for either two or five pairing sessions, those that underwent blockade of CRs by the NMDA receptor antagonist AP-5 in the second pairing session, and those that were pseudoconditioned for two or five sessions. These results are summarized in Figure 3. Acquisition curves for the three experimental groups that underwent conditioning are shown in Figure 3, A through C. Preparations conditioned for two pairing sessions obtained a mean of $56 \pm 38 \%$ CRs in the second session (Fig. 3A). Preparations conditioned for five sessions showed an asymptote of CRs in sessions three to five that averaged $56 \pm 26 \%$ CRs (Fig. 3B). The final group of preparations was first conditioned for one pairing session to a mean of $18 \pm 14 \%$ CRs. The NMDA receptor blocker AP-5 $(100 \mu \mathrm{M})$ was then applied to the bath, which resulted in blockade of the CRs to a mean of $1 \pm 2 \%$ CRs in session two (Fig. 3C). Western blots were performed on all experimental groups, and these findings are shown in Figure 3D. Egr-1 protein from preparations conditioned for two sessions averaged $225 \%$ of con-
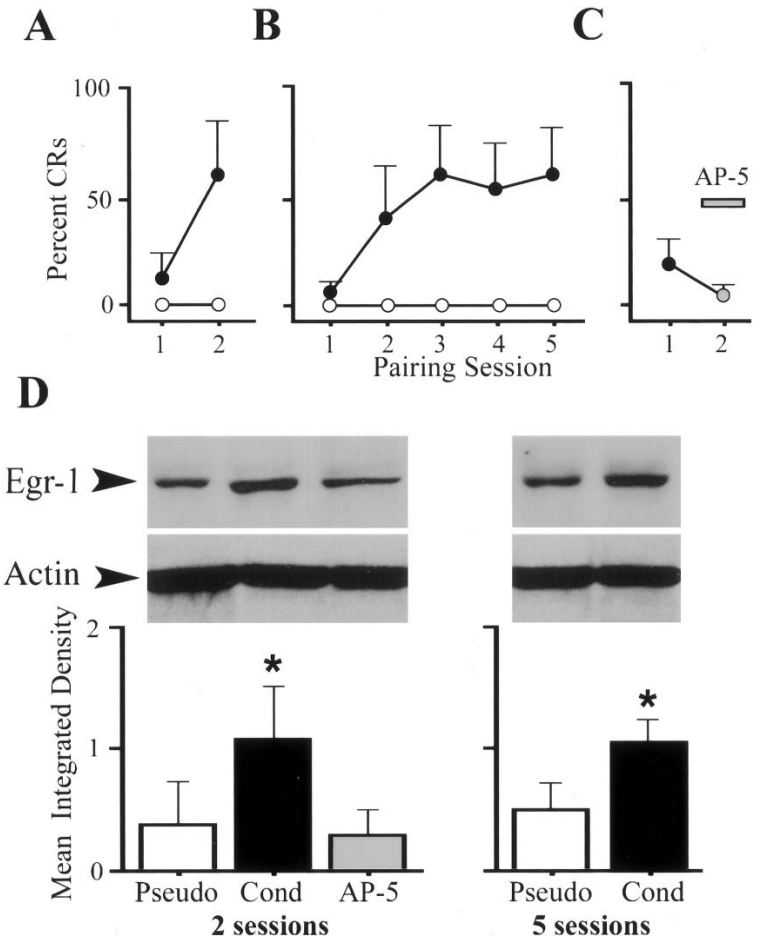

Figure 3. Western blot analysis of Egr-1 protein expression during conditioning and effects of AP-5. (A-C) Acquisition curves for preparations that were conditioned or pseudoconditioned for two $(A)$ or five $(B)$ pairing sessions, and for those treated with AP-5 in session two (C). While the conditioned groups showed CR acquisition of the training period, CRs after bath application of AP-5 were blocked. (D) Western blots showed that Egr-1 protein increased significantly in preparations conditioned for two sessions compared with those that were pseudoconditioned (asterisk). The AP-5-treated group showed protein values similar to the pseudoconditioned group. After five sessions, the level of Egr-1 protein remains significantly elevated after conditioning compared with controls. Representative bands for Egr-1 are shown as are actin loading controls.

trol values from pseudoconditioned cases $(P=0.004)$. Representative bands for Egr-1 and actin loading controls are shown for each group. Preparations that were treated with AP-5 demonstrated levels of Egr-1 protein similar to pseudoconditioned control levels $(P=0.71)$, suggesting that NMDA receptor activation is required for the enhanced expression of Egr-1 protein during conditioning. Preparations that were conditioned for five sessions also showed significantly greater Egr-1 protein, which averaged $208 \%$ of values obtained from preparations that were pseudoconditioned for five sessions $(P=0.02)$. There were no significant differences in protein bands for Egr-1 between the groups that underwent conditioning for two or five pairing sessions $(P=0.79)$. These data indicate that the enhanced levels of expression of Egr-1 protein in conditioned preparations after two sessions relative to controls remained significantly elevated after five sessions. A regression analysis of Egr-1 protein expression data with conditioning was also performed. While there was not a significant positive correlation between the level of Egr-1 protein and the level of conditioning after two pairing sessions $\left(R^{2}=0.3, P=0.21\right)$, this correlation was highly significant after five sessions $\left(R^{2}=0.5, P<0.001\right)$.

\section{Discussion}

The results show that the expression of the IEG-encoded protein Egr-1 is rapidly increased during a simple form of classical conditioning generated in vitro compared with pseudoconditioned controls. Moreover, protein expression remains significantly el- 
evated during the later stages of conditioning. Induction of Egr-1 protein during conditioning also requires NMDA receptor activation as it is blocked by the bath application of AP-5, which is also true of in vitro abducens classical conditioning. These findings suggest that this IEG inducible protein has a role in in vitro classical conditioning, perhaps in CR acquisition and in maintaining CR expression.

\section{Cellular localization of Egr-1}

The abducens motor nuclei of turtles were found to be immunopositive for Egr-1, and protein was localized predominantly in the cytoplasm compared with the nucleus. The cytoplasm of these neurons typically stained more intensely than did the nucleus. Immunoreactivity of abducens motor neurons for Egr-1 increased significantly after conditioning and resulted in enhanced labeling of the soma and dendritic processes compared with pseudoconditioned controls. Western blot analysis confirmed that expression of Egr-1 protein was significantly greater in conditioned preparations. Interestingly, Egr-1 immunoreactivity was not significantly enhanced in the principal sensory trigeminal nucleus after conditioning, another nucleus in the turtle eye blink circuitry that also receives convergent inputs from the CS and US (Zhu and Keifer 2004). These data suggest that the conditioning-related increase in Egr-1 immunoreactivity in response to the conditioning paradigm used here is specific for the abducens motor nuclei. Therefore, enhanced localization of Egr-1 protein after in vitro abducens conditioning occurs in the soma and dendrites where synaptic inputs from the trigeminal and auditory nerves are known to impinge (Keifer and Mokin 2004). Although there are sparse data describing the cellular localization of either mRNA or protein for Egr-1, a considerable amount is known about the expression of other IEGs, particularly Arc. Electron microscopic studies have shown the presence of polyribosomal clusters associated with dendritic spines of CNS neurons (Steward and Levy 1982). In the hippocampus, tetanic stimulation results in rapid redistribution of $\operatorname{Arc}$ mRNA with specific localization in synaptically activated dendritic segments after 15 min of stimulation (Steward et al. 1998; Steward and Worley 2001). Immunostaining of hippocampal tissue for Arc protein also indicates the presence of newly synthesized protein in the same dendritic segments (Steward et al. 1998), suggesting that Arc protein is selectively synthesized locally at activated synapses by utilizing synapse-associated polyribosomal complexes and dendritic mRNA. The NMDA receptor antagonists block the ability of stimulation to induce Arc protein synthesis (Steward and Worley 2001). Another IEG, BDNF (brain-derived neurotrophic factor), also depends on local rather than somatic protein synthesis for the induction of synaptic enhancement, allowing for direct local control of activated synapses on BDNF protein synthesis (Kang and Schuman 1996). A recent study also indicates that AMPA glutamate receptors GluR1 and GluR2 are locally synthesized in dendrites, delivered to synapses, and incorporated into the plasma membrane at or near synaptic sites by an activity-dependent mechanism (Ju et al. 2004). Based on these findings, protein synthesis in restricted cellular compartments provides a novel mechanism for the local regulation of synaptic plasticity (Steward and Worley 2002). The fact that Egr-1 immunoreactivity is enhanced in the soma and dendrites of abducens motor neurons that were conditioned is consistent with previous studies showing activity-dependent local protein synthesis, but whether this occurs during in vitro conditioning is unknown.

\section{Timing of Egr-1 expression in synaptic plasticity} and learning

Previous studies have demonstrated varying time courses of expression of Egr-1 during different behavioral paradigms. A spatial learning task in rats demonstrated that $E g r-1$ mRNA expression was rapid and transient (Guzowski et al. 2001). Egr-1 mRNA levels peaked $0.5 \mathrm{~h}$ after training and declined to control values in $6 \mathrm{~h}$. Similar findings for $E g r-1$ mRNA were observed following generalized brain stimulation in teleosts (Burmeister and Fernald 2005). This time course for learning or plasticity-related Egr-1 mRNA expression is similar to that described for Arc (Guzowski et al. 2001), but appears to be in contrast to more recent studies of Egr-1 mRNA expression during complex learning tasks. When using zif268 ${ }^{-1-}$ mutant mice, these animals were significantly impaired in an object recognition memory task when tested $48 \mathrm{~h}$ after training but not after $10 \mathrm{~min}$ (Bozon et al. 2003). These data suggest zif268 $8^{-1-}$ mutant mice are impaired in long-term memories but not short-term memories. Further scrutiny of this behavior in the same study revealed that zif $268^{-1-}$ mutant mice could adequately recall objects when overtrained and not exposed to the objects until a testing period days later. However, recognition memory failed when mice were re-exposed to the same objects and tested $24 \mathrm{~h}$ later. These findings suggest that zif $268^{-1-} \mathrm{mu}-$ tant mice are impaired in reconsolidation of recognition memories once retrieved. A similar function for $E g r-1$ was also proposed in a study of normal rats that received infusions of antisense oligonucleotides into the dorsal hippocampus (Lee et al. 2004).

In the present study, we found Egr-1 protein expression to increase dramatically shortly after the onset of conditioning in this in vitro preparation and remained significantly elevated in the late stages of conditioning. These data suggest that Egr-1 protein expression is induced during acquisition of abducens CRs, which generally occurs during the second pairing session and may function in cellular mechanisms of acquisition. The fact that both the CRs and Egr-1 protein expression are blocked by application of AP-5 suggests that protein expression is dependent on the activation of NMDA receptors as are the CRs. Electrical stimulation itself did not induce Egr-1 because protein levels were not elevated in pseudoconditioned preparations. Interestingly, Egr-1 protein remains elevated in the later stages of conditioning. These findings may be analogous to the association of Egr-1 expression with long-term memory and consolidation/ reconsolidation processes observed in behavioral studies of mammals. However, it is difficult to compare our late stages of conditioning, which is only after a period of $\sim 4 \mathrm{~h}$ in this study, with consolidation and certainly with reconsolidation processes. In previous studies, we have considered later pairing sessions (sessions 3-5) in our model to be representative of a post-acquisition phase. This is because CR acquisition asymptotes by about the third pairing session (Keifer 2001; Keifer et al. 2003; Mokin and Keifer 2004a; present study). Whether this later period of in vitro conditioning is analogous to a consolidation phase of memory is unknown. Perhaps a better comparison of our Egr-1 results might be made with findings from hippocampal LTP, another form of learning frequently studied in vitro. The results for LTP are also variable. Egr-1 expression has been shown to be up-regulated for a period of minutes to several hours after LTP induction in the dentate gyrus (Cole et al. 1989; Wisden et al. 1990). Expression has also been shown to be blocked by NMDA receptor antagonists (Cole et al. 1989), similar to our findings for conditioning. A more recent study using zif $268^{-1-}$ anesthetized mutant mice showed no deficits in either the induction or expression of LTP recorded for up to $60 \mathrm{~min}$ (Jones et al. 2001). However, a decline in late LTP was observed in the mutants $24 \mathrm{~h}$ later. Intermediate time periods were not tested. Induction of another IEG, Arc, following either electroconvulsive or LTP-inducing shock occurred in $30 \mathrm{~min}$; protein remained elevated at $4 \mathrm{~h}$ and returned to baseline levels by $8 \mathrm{~h}$ (Wallace et al. 1998; Guzowski et al. 2000). This time course is similar to induction of Egr-1 protein during abducens conditioning shown here. 


\section{Role for IEGs in receptor trafficking?}

The function of the IEGs in learning and memory processes is unknown, and the data so far suggest many possibilities. Some studies have suggested that IEGs regulate activity-dependent AMPA receptor trafficking. The most convincing evidence in favor of this hypothesis comes from studies of the IEG Narp, which is an essential factor in AMPA receptor clustering at excitatory synapses in culture ( $\mathrm{O}^{\prime}$ Brien et al. 2002). We have become interested in cellular mechanisms of receptor insertion and deletion at synapses due to our observations that GluR4 subunits of the AMPA receptor are specifically up-regulated in abducens motor neurons during in vitro conditioning (Keifer 2001; Keifer and Clark 2003). Moreover, GluR4-containing AMPA receptors are targeted to synaptic sites during conditioning, and this is blocked by AP-5 (Mokin and Keifer 2004a). NR1 subunits of the NMDA receptor are unchanged at synaptic sites after conditioning or AP-5 treatment. The abducens motor neurons of turtles are considered to be potential sites of CR acquisition because they receive direct convergent inputs from the nerves that relay the CS and US and therefore may utilize a Hebbian-like plasticity mechanism (Keifer and Mokin 2004). This arrangement may be different from that described in rabbits (Krupa et al. 1996). Preliminary observations from our laboratory of Arc protein by using confocal microscopy and coimmunoprecipitation reveal that it is transiently colocalized with GluR4 subunits in abducens motor neurons during acquisition of CRs (Mokin and Keifer 2004b). The data are suggestive that Arc may have a regulatory role in delivery of GluR4 to synapses. While similar experiments for Egr-1 have not yet been performed, one possible role of the IEG inducible proteins may be in activity-dependent synaptic modification by regulation of receptor distribution.

\section{Materials and Methods}

\section{Conditioning procedures}

Freshwater pond turtles, Pseudemys scripta elegans $(n=47)$, obtained from commercial suppliers were anesthetized by hypothermia and decapitated. Protocols involving the use of animals complied with the guidelines of the National Institutes of Health and the Institutional Animal Care and Use Committee. The brain stem was transected at the levels of the trochlear and glossopharyngeal nerves, and the cerebellum was removed as described previously (Anderson and Keifer 1999). Therefore, the preparation consisted only of the pons with the cerebellar circuitry, including the red nucleus, removed. The brain stem was bathed in physiological saline $(2-4 \mathrm{~mL} / \mathrm{min}$ ) containing (in $\mathrm{mM}$ ): 100 $\mathrm{NaCl}, 6 \mathrm{KCl}, 40 \mathrm{NaHCO}_{3}, 2.6 \mathrm{CaCl}_{2}, 1.6 \mathrm{MgCl}_{2}$, and 20 glucose, which was oxygenated with $95 \% \mathrm{O}_{2} / 5 \% \mathrm{CO}_{2}$ and maintained at room temperature $\left(22^{\circ} \mathrm{C}-24^{\circ} \mathrm{C}\right.$ ) (Anderson and Keifer 1997, 1999). Suction electrodes were used for stimulation and recording of cranial nerves. The US was an approximately two times threshold single-shock stimulus applied to the trigeminal nerve; the CS was a subthreshold $100-\mathrm{Hz}, 1-\mathrm{s}$ train stimulus applied to the ipsilateral posterior root of the eighth nerve that was an average of $73 \%$ of the threshold amplitude required to produce activity in the abducens nerve (Keifer et al. 1995; Anderson and Keifer 1997, 1999; Keifer 2001). The latter nerve will be referred to as the auditory nerve as it carries predominantly auditory fibers. Neural activity was recorded from the ipsilateral abducens nerve, which projects to the extraocular muscles controlling movements of the eye and eyelid. The CS-US interval used in this study was $20 \mathrm{msec}$, which is defined as the time between the offset of the CS and the onset of the US. This interval was previously found to be optimal for acquisition of abducens CRs and conditioning fails to occur with intervals $>100 \mathrm{msec}$ (Keifer 2001). The intertrial interval between the paired CS and US was 30 sec. A pairing session consisted of 50 CS-US presentations followed by a 30-min rest period, in which there was no stimulation. CRs were defined as abducens nerve activity that occurred during the CS and exceeded the amplitude of double the baseline recording level. At the end of the conditioning experiments, preparations for immunocytochemistry were immersion fixed in cold 3\% paraformaldehyde, whereas those for Western blot analysis were flash frozen in liquid nitrogen and stored at $-70^{\circ} \mathrm{C}$.

\section{Pharmacology}

The NMDA receptor antagonist D,L-2-amino-5-phosphonovaleric acid (AP-5; $100 \mu \mathrm{M}$; Tocris Cookson) was dissolved in physiological saline and perfused through the bath. Preparations $(n=5)$ underwent the conditioning procedure in normal physiological saline for one pairing session, and all responded with CRs. After the first session AP-5 was perfused through the bath 35 min prior to the beginning of the second pairing session and remained in the bath for one pairing session, at which time expression of CRs was blocked in all preparations.

\section{Immunocytochemistry and image analysis}

Four groups of preparations were examined with immunocytochemistry: those that were presented with paired stimuli and were conditioned for two $(n=6)$ or five $(n=5)$ pairing sessions, and those that were presented with randomly unpaired pseudoconditioning stimuli for two $(n=6)$ or five $(n=5)$ sessions. Tissue sections were cut at $30 \mu \mathrm{m}$ and preincubated in $10 \%$ normal goat serum for $1 \mathrm{~h}$ followed by incubation in primary antibody overnight at $4^{\circ} \mathrm{C}$ with gentle shaking. The primary antibody used was a polyclonal raised in rabbit that recognizes the carboxy terminus of Egr-1 (sc-110, Santa Cruz Biotechnology; concentration 1: 1000). Following the primary antibody, sections were incubated with secondary antibody for $2 \mathrm{~h}$ by using a concentration of 1:100. The secondary antibody was a Cy3-conjugated goat antirabbit IgG (Jackson ImmunoResearch). The specificity of the Egr-1 primary antibody was tested by performing Western blotting on turtle and rat brain tissue (see Results). The secondary antibody was tested for specificity by omission of the primary antibody or incubation with an incompatible secondary, as described by Keifer and Carr (2000). After incubation in the secondary antibody, the sections were rinsed and mounted on slides, air-dried overnight, and coverslipped. To analyze immunoreactivity of the principal and accessory abducens motor nuclei to Egr-1, digital images of immunofluorescence were obtained by using a Zeiss Axioskop microscope equipped with an Axiocam color camera. Image analysis was performed by using Adobe Photoshop software, where the average luminosity level \pm SD of the pixels in the selected field was calculated (Keifer 2001; Keifer et al. 2003; Lindahl and Keifer 2004; Meyer et al. 2004). Each selected field encompassed the cell bodies of the principal or accessory abducens motor nuclei ipsilateral to the side that was conditioned, and values of intensity of label were obtained for each tissue section analyzed. Background values were taken from unlabeled areas in the same section and were subtracted from signal in the abducens nuclei for every section analyzed to control for variations in staining. Generally, 6-10 sections were analyzed and averaged for each case. A similar approach was used by others (Ouyang et al. 1999). StatView software was used for statistical analysis by using ANOVA, and values are reported as mean \pm SEM.

\section{Western blot analysis}

For Western blotting, brain stem preparations underwent conditioning for two $(n=4)$ or five $(n=5)$ sessions, or pseudoconditioning for two $(n=4)$ or five $(n=5)$ sessions. Tissue was homogenized and homogenates centrifuged at $1000 \mathrm{~g}$ for $10 \mathrm{~min}$ at $4^{\circ} \mathrm{C}$ and supernatants recentrifuged at $20,000 \mathrm{~g}$ for $20 \mathrm{~min}$. Pellets were resuspended in ice-cold HPLC grade water, spun at $7600 \mathrm{~g}$, resuspended again in HPLC grade water, and clarified by centrifugation at $48,000 \mathrm{~g}$ for $20 \mathrm{~min}$ at $4^{\circ} \mathrm{C}$. Final pellets were resuspended in $50 \mathrm{mM}$ HEPES buffer (pH 7.4), aliquoted, and stored at $-70^{\circ} \mathrm{C}$. Protein sample concentrates were solubilized in $1 \times \mathrm{SDS} /$ $\beta$-mercaptoethanol and boiled for $3 \mathrm{~min}$ prior to separation by $6 \%$ SDS-PAGE. Following electrophoresis, membranes were blocked with 5\% nonfat dry milk in PBS/0.1\% Tween-20 for $4 \mathrm{~h}$ 
at $4^{\circ} \mathrm{C}$. The membranes were incubated with primary antibodies to Egr-1 (1:500) overnight in PBS/0.1\% Tween-20/0.1\%BSA at $4^{\circ} \mathrm{C}$, washed, and incubated within HRP-conjugated goat antirabbit IgG $(1: 100,000)$ for $2 \mathrm{~h}$ at room temperature. Loading controls were performed by using primary antibodies to actin (1:500; Chemicon). Proteins were detected by using the ECL-Plus chemiluminescence system (Amerisham Pharmacia). Immunoreactive signals were captured on Kodak X-omatic AR film and quantified by computer-assisted densitometry.

\section{Acknowledgments}

Supported by National Institutes of Health grants MH58709 and P20 RR015567, which is designated as a Center of Biomedical Research Excellence (COBRE) to J.K.

\section{References}

Anderson, C.W. and Keifer, J. 1997. The cerebellum and red nucleus are not required for in vitro classical conditioning of the turtle abducens nerve response. J. Neurosci. 17: 9736-9745.

. 1999. Properties of conditioned abducens nerve responses in a highly reduced in vitro brain stem preparation from the turtle. $J$. Neurophysiol. 81: 1242-1250.

Bozon, B., Davis, S., and Laroche, S. 2003. A requirement for the immediate early gene zif268 in reconsolidation of recognition memory after retrieval. Neuron 40: 695-701.

Bracha, V., Irwin, K.B., Wester, M.L., Wunderlich, D.A., Stachowiak, M.K., and Bloedel, J.R. 1998. Microinjections of anisomycin into the intermediate cerebellum during learning affect the acquisition of classically conditioned responses in the rabbit. Brain Res. 788: $169-178$

Brauth, S., Liang, W., Roberts, T.F., Scott, L.L., and Quinlan, E.M. 2002. Contact call-driven zenk protein induction and habituation in telencephalic auditory pathways in the budgerigar (Melopsittacus undulatus): Implications for understanding vocal learning processes. Learn. Mem. 9: 76-88.

Burmeister, S.S. and Fernald, R.D. 2005. Evolutionary conservation of the Egr-1 immediate-early gene response in a teleost. J. Comp. Neurol. 481: 220-232.

Carrive, P., Kehoe, E.J., Macrae, M., and Paxinos, G. 1997. Fos-like immunoreactivity in locus coeruleus after classical conditioning of the rabbit's nictitating membrane response. Neurosci. Lett. 223: 33-36.

Christian, K.M. and Thompson, R.F. 2003. Neural substrates of eyeblink conditioning: Acquisition and retention. Learn. Mem. 11: 427-455.

Clark, R.E., Manns, J.R., and Squire, L.R. 2002. Classical conditioning, awareness, and brain systems. Trends Cogn. Sci. 6: 524-531.

Cole, A.J., Saffen, D.W., Baraban, J.M., and Worley, P.F. 1989. Rapid increase of an immediate early gene messenger RNA in hippocampal neurons by synaptic NMDA receptor activation. Nature 340: $474-476$

Guzowski, J.F., Lyford, G.L., Stevenson, G.D., Houston, F.P., McGaugh, J.L., Worley, P.F., and Barnes, C.A. 2000. Inhibition of activity-dependent Arc protein expression in the rat hippocampus impairs the maintenance of long-term potentiation and the consolidation of long-term memory. J. Neurosci. 20: 3993-4001.

Guzowski, J.F., Setlow, B., Wagner, E.K., and McGaugh, J.L. 2001. Experience-dependent gene expression in the rat hippocampus after spatial learning: A comparison of the immediate-early genes Arc, c-fos, and zif268. J. Neurosci. 21: 5089-5098.

Irwin, K.B., Craig, A.D., Bracha, V., and Bloedel, J.R. 1992. Distribution of c-fos expression in brainstem neurons associated with conditioning and pseudo-conditioning of the rabbit nictitating membrane reflex. Neurosci. Lett. 148: 71-75.

Jones, M.W., Errington, M.L., French, P.J., Fine, A., Bliss, T.V.P., Garel, S., Charnay, P., Bozon, B., Laroche, S., and Davis, S. 2001. A requirement for the immediate early gene zif268 in the expression of late LTP and long-term memories. Nat. Neurosci. 4: 289-296.

Ju, W., Morishita, W., Tsui, J., Gaietta, G., Deerinck, T.J., Adams, S.R., Garner, C.C., Tsien, R.Y., Ellisman, M.H., and Malenka, R.C. 2004 Activity-dependent regulation of dendritic synthesis and trafficking of AMPA receptors. Nat. Neurosci. 7: 244-253.

Kang, H. and Schuman, E.M. 1996. A requirement for local protein synthesis in neurotrophin-induced hippocampal synaptic plasticity. Science 273: 1402-1406.

Keifer, J. 2001. In vitro eye-blink classical conditioning is NMDA receptor-dependent and involves redistribution of AMPA receptor subunit GluR4. J. Neurosci. 21: 2434-2441.

. 2003. In vitro classical conditioning of the turtle eyeblink reflex: Approaching cellular mechanisms of acquisition. Cerebellum 2: $55-61$.
Keifer, J. and Carr, M.T. 2000. Immunocytochemical localization of glutamate receptor subunits in the brain stem and cerebellum of the turtle Chrysemys picta. J. Comp. Neurol. 427: 455-468.

Keifer, J. and Clark, T.G. 2003. Abducens conditioning in in vitro turtle brain stem without cerebellum requires NMDA receptors and involves upregulation of GluR4 containing AMPA receptors. Exp. Brain Res. 151: 405-410.

Keifer, J. and Mokin, M. 2004. Distribution of anterogradely labeled trigeminal and auditory nerve boutons on abducens motor neurons in turtles: Implications for in vitro classical conditioning. J. Comp. Neurol. 471: 144-152.

Keifer, J., Armstrong, K.E., and Houk, J.C. 1995. In vitro classical conditioning of abducens nerve discharge in turtles. J. Neurosci. 15: $5036-5048$

Keifer, J., Brewer, B.T., Meehan, P.E., Brue, R.J., and Clark, T.G. 2003. Role for calbindin-D28K in in vitro classical conditioning of abducens nerve responses in turtles. Synapse 49: 106-115.

Kleim, J.A., Freeman Jr., J.H., Bruneau, R., Nolan, B.C., Cooper, N.R., Zook, A., and Walters, D. 2002. Synapse formation is associated with memory storage in the cerebellum. PNAS 99: 13228-13231.

Krupa, D.J., Weng, J., and Thompson, R.F. 1996. Inactivation of brainstem motor nuceli blocks expression but not acquisition of the rabbit's classically conditioned eyeblink. Behav. Neurosci. 110: $219-227$.

Lee, J.L.C., Everitt, B.J., and Thomas, K.L. 2004. Independent cellular processes for hippocampal memory consolidation and reconsolidation. Science 304: 839-843.

Lindahl, J.S. and Keifer, J. 2004. Glutamate receptor subunits are altered in forebrain and cerebellum in rats chronically exposed to the NMDA receptor antagonist phencyclidine. Neuropsychopharmacology 29: 2065-2073.

Mello, C., Nottebohm, F., and Clayton, D. 1995. Repeated exposure to one song leads to a rapid and persistent decline in an immediate early gene's response to that song in zebra finch telencephalon. $J$. Neurosci. 15: 6919-6925.

Meyer, W.N., Keifer, J., Korzan, W.J., and Summers, C.H. 2004. Social stress and corticosterone regionally upregulate limbic N-methyl-D-aspartate receptor subunit type NR2A and NR2B in the lizard Anolis carolinensis. Neuroscience 128: 675-684.

Mokin, M. and Keifer, J. 2004a. Targeting of GluR4-containing AMPA receptors to synaptic sites during in vitro classical conditioning. Neuroscience 128: 219-228.

. 2004b. Expression of the immediate early gene proteins Arc and Egr-1 during in vitro eyeblink classical conditioning in turtles. Abstract Viewer Itinerary Planner, Program No. 512.14. Society for Neuroscience, Washington, DC.

O'Brien, R., Xu, D., Mi, R., Tang, X., Hopf, C., and Worley, P. 2002. Synaptically targeted Narp plays an essential role in the aggregation of AMPA receptors at excitatory synapses in cultured spinal neurons. J. Neurosci. 22: 4487-4498.

O'Donovan, K.J., Tourtellotte, W.G., Millbrandt, J., and Baraban, J.M 1999. The EGR family of transcription-regulatory factors: Progress at the interface of molecular and systems neuroscience. TINS 22: $167-173$.

Ouyang, Y., Rosenstein, A., Kreiman, G., Schuman, E.M., and Kennedy M.B. 1999. Tetanic stimulation leads to increased accumulation of $\mathrm{Ca}^{2+} /$ calmodulin-dependent protein kinase II via dendritic protein synthesis in hippocampal neurons. J. Neurosci. 19: 7823-7833.

Steward, O. and Levy, W.B. 1982. Preferential localization of polyribosomes under the base of dendritic spines in granule cells of the dentate gyrus. J. Neurosci. 2: 284-291.

Steward, O. and Worley, P.F. 2001. Selective targeting of newly synthesized Arc mRNA to active synapses requires NMDA receptor activation. Neuron 30: $227-240$.

- 2002. Local synthesis of proteins at synaptic sites on dendrites: role in synaptic plasticity and memory consolidation? Neurobiol. Learn Mem. 78: 508-527.

Steward, O., Wallace, C.S., Lyford, G.L., and Worley, P.F. 1998. Synaptic activation causes the mRNA for the IEG Arc to localize selectively near activated postsynaptic sites on dendrites. Neuron 21: 741-751.

Wallace, C.S., Lyford, G.L., Worley, P.F., and Steward, O. 1998. Differential intracellular sorting of immediate early gene mRNAs depends on signals in the mRNA sequence. J. Neurosci. 18: 26-35.

Wisden, W., Errington, M.L., Williams, S., Dunnett, S.B., Waters, C., Hitchcock, D., Evan, G., Bliss, T.V., and Hunt, S.P. 1990. Differential expression of immediate early genes in the hippocampus and spinal cord. Neuron 4: 603-614.

Zhu, D. and Keifer, J. 2004. Pathways controlling trigeminal and auditory nerve-evoked abducens eyeblink reflexes in pond turtles. Brain Behav. Evol. 64: 207-222.

Received October 7, 2004; accepted in revised form February 16, 2005. 


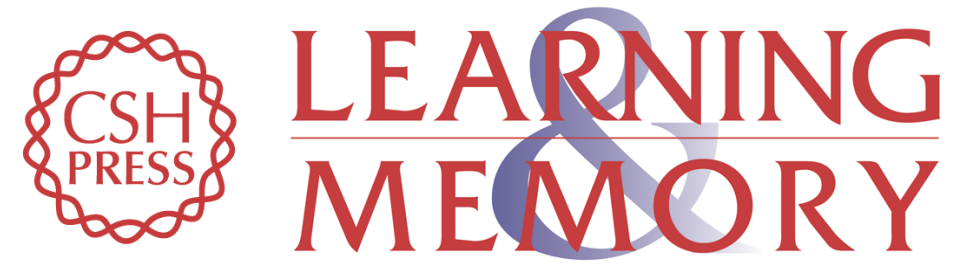

\section{Expression of the immediate-early gene-encoded protein Egr-1 ( zif268) during in vitro classical conditioning}

Maxim Mokin and Joyce Keifer

Learn. Mem. 2005, 12:

Access the most recent version at doi:10.1101/lm.87305

References This article cites 39 articles, 13 of which can be accessed free at: http://learnmem.cshlp.org/content/12/2/144.full.html\#ref-list-1

License

Email Alerting Receive free email alerts when new articles cite this article - sign up in the box at the Service top right corner of the article or click here. 